\title{
Liquid Column Deformation and Particle Size Distribution in Gas Atomization
}

\section{Georgios S. E. Antipas}

Department of Mining Engineering and Metallurgy National Technical University of Athens Zografou Campus, Athens, Greece. Email: yantipas@otenet.gr

Received December 22 $2^{\text {nd }}, 2010$; revised January $5^{\text {th }}, 2011$; accepted February $12^{\text {th }}, 2011$.

\begin{abstract}
A water-gas flow injected by a close coupled atomizer was studied via High Speed Photography and Phase Doppler Anemometry. The formation of a wave disturbance on the surface of the water column was confirmed. The flow converged within an area approximately $3 \mathrm{~mm}$ in diameter, independent of atomization conditions. The particle size distribution across the spray suggested a trend of decreasing particle sizes and particle velocities with increasing distance from the spray axis of symmetry.
\end{abstract}

Keywords: Liquid Column Deformation, Two Phase Flow, Atomization, High Speed Photography, Laser Doppler Anemometry

\section{Introduction}

During close coupled atomization, a liquid column or sheet is perturbed by a high velocity gas flow and is broken up into droplets, in a two stage process. In the first stage, that of primary atomization [1], the surface of the melt is disturbed by a sinusoidal oscillation [2] and is subsequently broken up into large drops or unstable bodies, the ligaments [3]. During the subsequent stage of secondary atomization, the drops/ligaments may further disintegrate in flight, either via a low-turbulence mechanism [4] or in a more chaotic high-turbulence stripping fashion [5]. The principle of gas atomization is shown in Figure 1. In spray forming, atomization of a molten metal or alloy causes rapid solidification of the drops in flight. The spray's subsequent impingement on a substrate produces a spray cast of varying microstructure. It is in fact the localized size distribution of particle diameters inside the spray, which dictates the spray cast microstructure and mechanical properties. In turn, local size distributions depend on the break up mechanisms. The latter, have received considerable attention in earlier phenomenological studies [4-14] in respect to atomization parameters - such as nature of the gas and melt phase, gas injection pressures and melt superheat. More recently, experimental treatises of atomizing geometries have been presented [15-16]. Liquid break up phenomena, however - although described in the macro scale early on (e.g. [17-20]) - have not been reflected on rigorous modeling implementations. Modern atomization modeling ap-

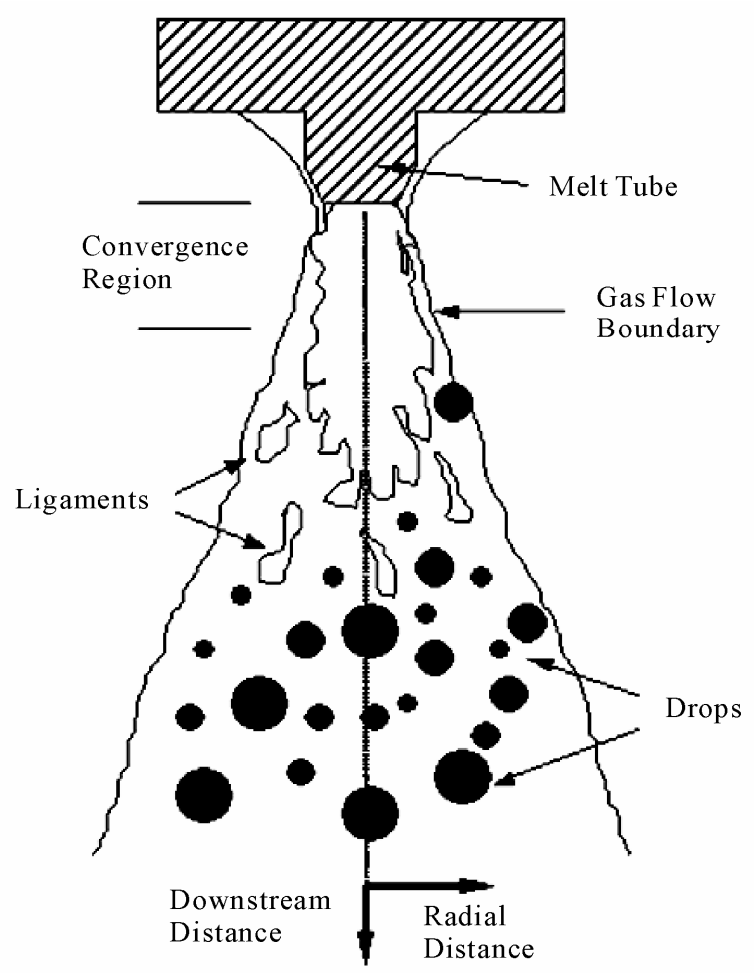

Figure 1. The principle of atomization. 
pears to be focusing on CPU-intensive stochastic simulation of the liquid jet and primary atomization in terms of Reynolds- averaged Navier-Stokes mixing (e.g. [21]). Recently, the more realistic cases of turbulent atomization conditions have been addressed - e.g. by CFD (see [22-24]) and integrated models [15] have been proposed.

The current study investigates the initial stage of turbulent mixing in a close coupled atomizer, which is assumed to take place within a finite convergence region; this region constitutes a crucial subtlety of a flexible mathematical model for the atomization of liquid metals already presented elsewhere [25]. The model - covering both primary and secondary atomization - is applicable to any liquid//gas system and is based on the formation of sinusoidal traveling waves along the surface of a liquid $[26,27]$. Estimation of the convergence region diameter is of great importance to modeling of the gas flow [28], as it determines the Mach number, static temperature and sonic velocities of the gas inducing break up of the liquid column.

\section{Experimental Procedure}

A cross section of the close coupled assembly used in this study is shown in Figure 2. The atomizer consisted of 20 gas jets arranged in a ring configuration. Each jet outlet diameter was $0.75 \mathrm{~mm}$ and its each inclination from the vertical direction was $20^{\circ}$.

\subsection{High Speed Photography}

The behavior of a water column perturbed by Nitrogen and Helium gases was studied. The choice of water as the atomized medium was due to its low viscosity, which in turn was expected to lead to the formation of larger surface wave amplitudes for a given gas velocity, as outlined in [25]. An Imacon 790 high speed camera fitted with a Nikon micro-Nikkor $55 \mathrm{~mm}$ lens was used; the camera was capable of speeds ranging between 104 and 107 frames per second. An intermediate tube of $21 \mathrm{~mm}$ between the lens and the aperture offered a fixed magnification of $\times 1.5$. The diameter of the water column was either 2 or $3 \mathrm{~mm}$. The experiments were conducted in ambient pressure $(0.1 \mathrm{MPa})$ and temperature $\left(17^{\circ} \mathrm{C}\right)$. The high speed frames presented in this study are based on original photographs in which the contrast between the actual water column and the background has been enhanced by means of response curve filtering. The experimental assembly used in the high speed photography studies is shown in Figure 3.

\subsection{Phase Doppler Anemometry (PDA)}

The dynamic history of moving water particles during atomization was studied by a Dantec Particle Dynamics Analyser. The system is based on the Phase Doppler principle for non-intrusive real time measurements of a wide range of particle sizes. An Ar-ion laser with a maximum output of $5 \mathrm{~W}$ was employed, capable of measuring particles in the range of $1-1000 \mu \mathrm{m}$ over $1.2 \mathrm{~m}$ away from the source with an error of $4 \%$. The maximum measurable velocity was $500 \mathrm{~m} / \mathrm{s}$ with an error of $1 \%$. The output included the mean and turbulent components of particle velocities in the downstream and radial direction of the flow, the mass flux inside the measurement volume and a number of characteristic mean diameters such as the $\mathrm{D}_{32}$ (Sauter) particle size. The disintegration of a water column $3 \mathrm{~mm}$ in diameter atomized by Nitrogen, Argon and Helium gases at a pressure of 100 psi $(0.68 \mathrm{MPa})$ was studied. A fixed $70^{\circ}$ angle was main-

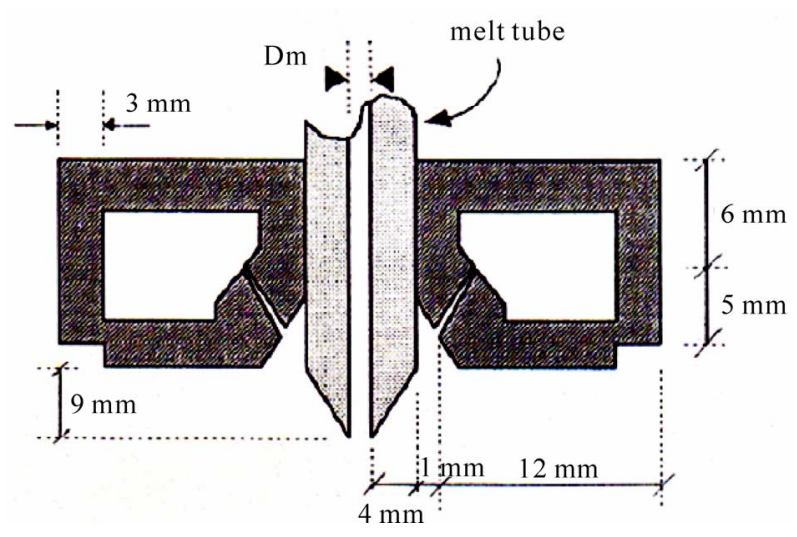

Figure 2. Geometry of the close coupled atomizer.

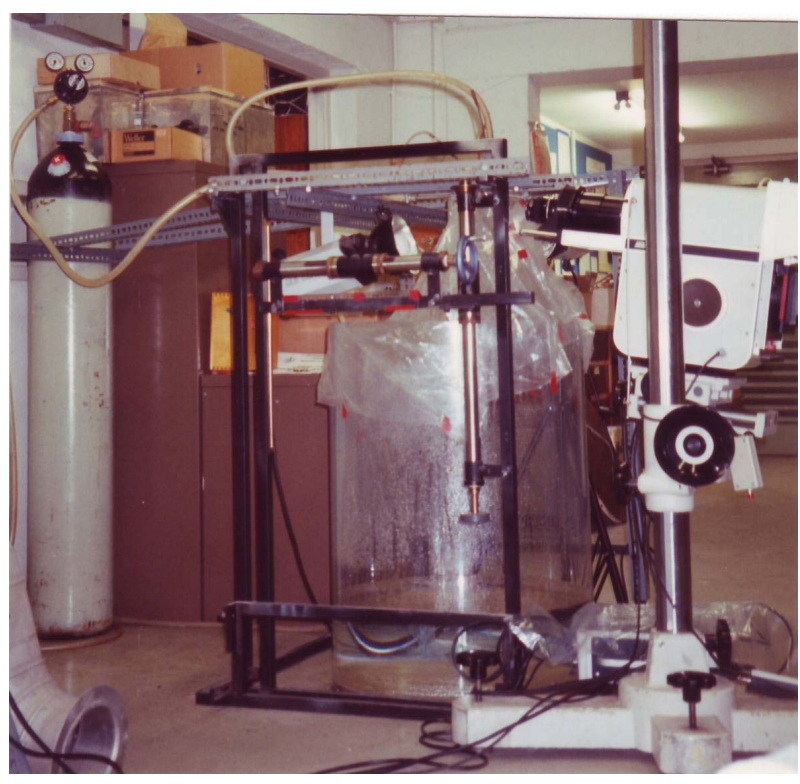

Figure 3. High speed photography assembly. 
tained between the laser source and the detector. A fixed horizontal spacing of $600 \mathrm{~mm}$ was kept between the detector and the point of convergence of the individual laser beams. The Phase Doppler apparatus used in this study is shown in Figure 4.

\section{Results and Discussion}

\subsection{High Speed Photography}

The flow was studied between the tip of the melt tube and approximately $12 \mathrm{~mm}$ below the melt tube.

Atomization and complete disintegration of the water column was found to depend strongly on the velocities of the two phases. With reducing initial water velocity, break up of the column was more complete further upstream. A low water velocity amounts to a high relative velocity between the melt and gas phase and a correspondingly high growth rate of the surface disturbance [25]. Higher growth rates also mean that the time required for the instability to acquire sufficiently large amplitudes is relatively large and as a result, the break up length of the jet is correspondingly decreased. Figures 5(a) and (b) give supporting evidence. In the case of water issuing from the delivery tube at a velocity of $7 \mathrm{~m} / \mathrm{s}$ atomized by Nitrogen at $20 \mathrm{psi}(0.14 \mathrm{MPa})$, the conical spray jet is formed at the tip of the tube - see Figure 5(a) - while at a higher water velocity of $13 \mathrm{~m} / \mathrm{s}$ - e.g. Figure 5(b) - there is an unbroken core of water $6 \mathrm{~mm}$ in length before the formation of the spray cone. At sufficiently high melt velocities and at relatively low gas pressures the column exhibited a tendency for sinusoidal antisymmetric oscillations, as shown in Figure 5(c).

Superimposed on the antisymmetric mode, oscillations of the symmetric type, as shown in Figure 5(d) gave rise to the formation of crests which normally led to the detachment of fragments from the disturbed column surface, shown in Figure 5(e). The symmetric instability amplitudes were an order of magnitude smaller than those of the antisymmetric type. An increase in the diameter of the water column caused a reduction in the wavelengths disturbing the surface of the water column. This in turn led to the disintegration of the column further downstream from the point of initial atomization.

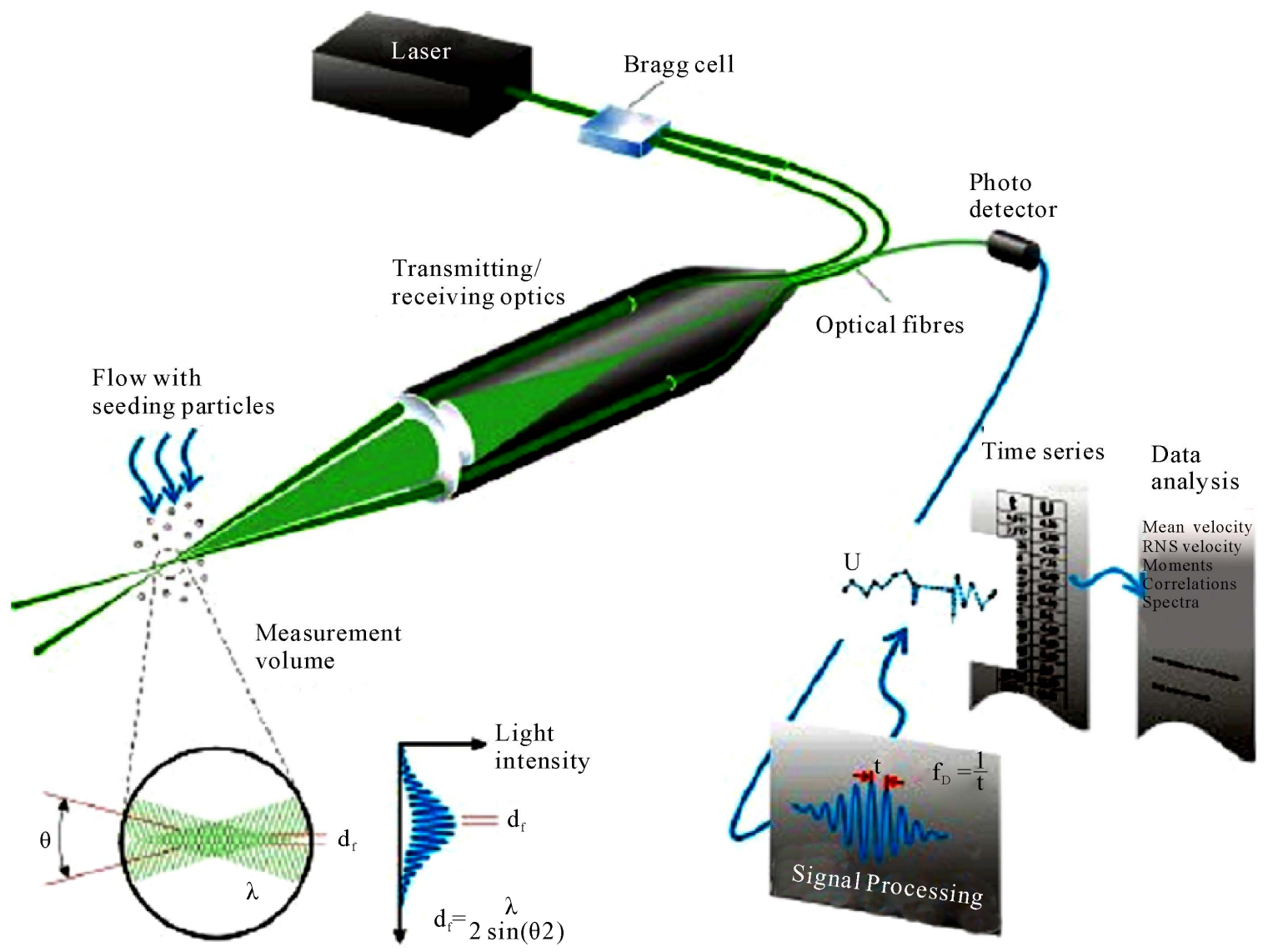

Figure 4. Phase Doppler Anemometry apparatus. 


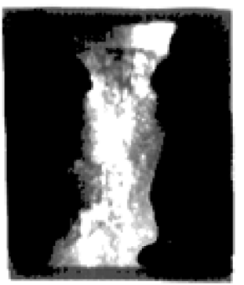

(a)

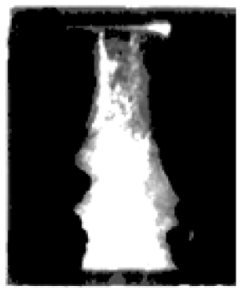

(b)

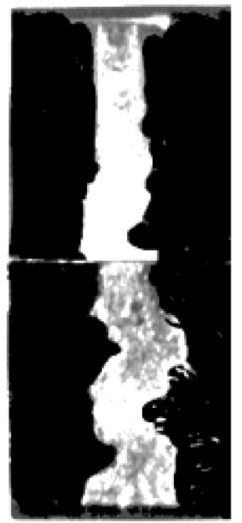

(c)

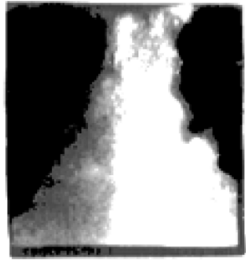

(d)

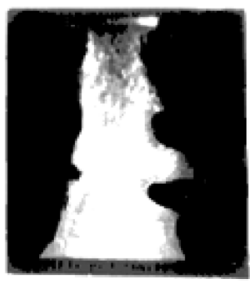

(e)

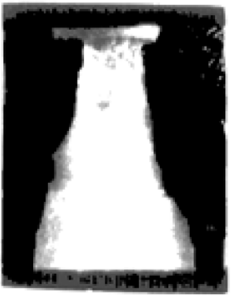

(f)
Figure 5. (a) Water $(2 \mathrm{~mm})$ at $7 \mathrm{~m} / \mathrm{s}, \mathrm{N}_{2}$ at $20 \mathrm{psi}, 2.5 * 104$ frames/s; (b) Water $(2 \mathrm{~mm})$ at $13 \mathrm{~m} / \mathrm{s}, \mathrm{N}_{2}$ at $20 \mathrm{psi}, 2.5 * 104$ frames/s; (c) Water $(2 \mathrm{~mm})$ at $13 \mathrm{~m} / \mathrm{s}, \mathrm{N}_{2}$ at $10 \mathrm{psi}, 2.5 * 104$ frames/s; (d) Water $(2 \mathrm{~mm})$ at $13 \mathrm{~m} / \mathrm{s}$, He at $50 \mathrm{psi}, 105$ frames/s; (e) Water $(3 \mathrm{~mm})$ at $7 \mathrm{~m} / \mathrm{s}, \mathrm{N}_{2}$ at $30 \mathrm{psi}, 106$ frames/s; (f) Water $(3 \mathrm{~mm})$ at $7 \mathrm{~m} / \mathrm{s}, \mathrm{N}_{2}$ at $30 \mathrm{psi}, 105$ frames $/ s$.

Formation of a conical spray jet a certain distance below the point of convergence of the gas jets was always a predominant feature. This seemingly uniform spray jet initiated approximately $5 \mathrm{~mm}$ downstream from the tip of the water delivery tube for any set of experimental parameters. The angle of the jet was constant and roughly equal to $20^{\circ}$ as long as turbulent conditions for the gas phase were satisfied - see Figure 5(f). In general, no crest observed reached amplitude greater than the water column radius. The diameter of the convergence region, taken to be the point at which the spray jet appeared to have the smallest diameter, was also measured on every photograph and was found to be equal to a constant value of $3 \mathrm{~mm}$. This diameter was found to be independent of the radius of the water column, the type of atomizing gas and the injection pressure.

\subsection{Phase Doppler Anemometry}

In the water sprays examined by PDA, the radial distribution of drops $40 \mathrm{~mm}$ downstream from the tip of the melt tube was always found to be irregular. Figures 6(a), (b) and (c), for Nitrogen, Argon and Helium flows respectively, suggest that the coarser fragments of the spray lie in close proximity of the central axis, defined as the point of maximum flux and their diameter decreases with increasing distance from the central axis. The assumption of maximum particle flux along the centre axis

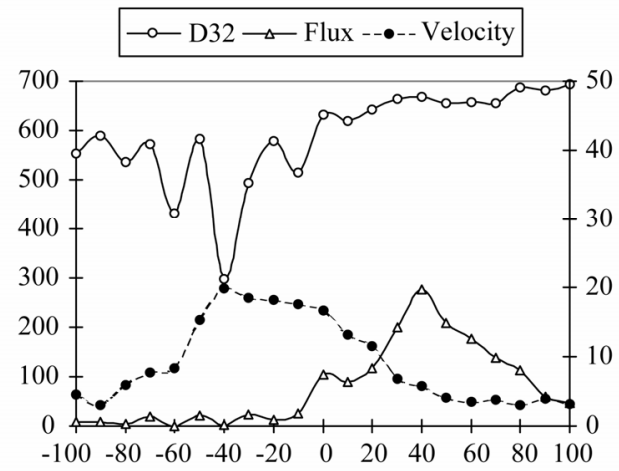

(a)

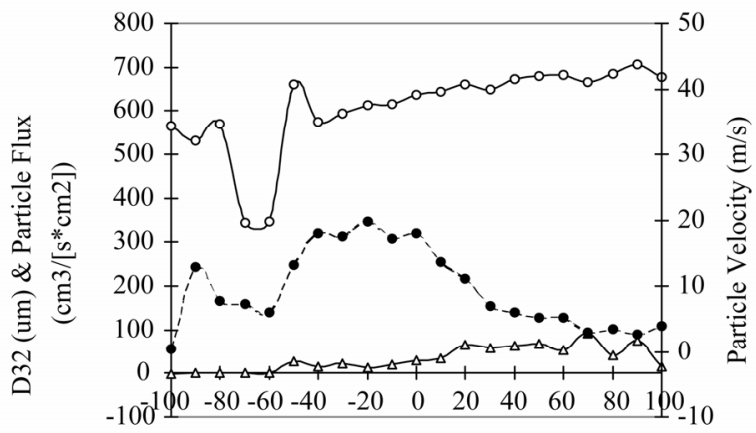

(b)

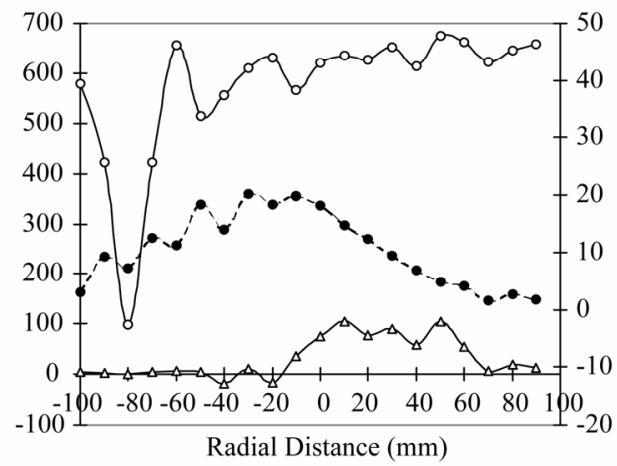

(c)

Figure 6. Radial distribution of particle size, velocity and volume flux for water atomized by: (a) $\mathrm{N}_{2}$ at 50 psi (0.34 MPa); (b) Ar at 50 psi; (c) He at 50 psi. 
of the spray has been experimentally confirmed by spray forming experiments of Al alloys [29]. In addition, it has been shown that particle sizes monotonically decrease with distance from the centre of the flow [25]. The profiles in Figure 6 may appear asymmetric due to the mismatch between the vertical axis of motion of the PDA apparatus and the actual vertical axis of symmetry of the spray. It is unlikely that the two axes can be made to overlap, due to the highly turbulent nature of the flow which causes the spray's axis of symmetry to fluctuate. The largest measured diameters produced by Nitrogen and Argon, Figures 6(a) and (b) respectively, were of the order of $700 \mu \mathrm{m}$, while Helium, as shown in Figure 6(c), produced finer particles. Numerical data underlying to Figure 6 are presented in, Table 1.

Variation of the $\mathrm{D}_{32}$ particle size and the mean downstream particle velocity as a function of distance from the point of initial atomization are shown in Figures 7(a) and (b), for Nitrogen and Argon respectively. Comparison of the two plots suggests that the spray in its infancy contained globules of diameter $550 \mu \mathrm{m}$ in the case of Nitrogen and $600 \mu \mathrm{m}$ in the case of Argon. The nature of the gas did not substantially influence the products of primary atomization at this pressure, since the initial drop

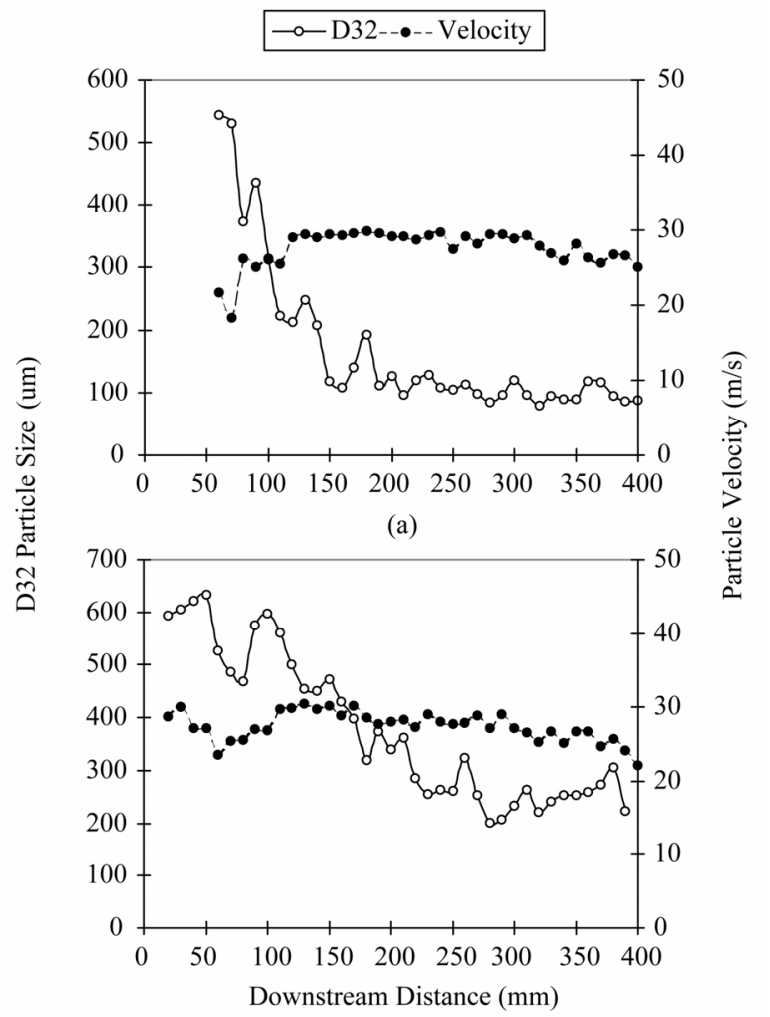

(b)

Figure 7. Variation of particle velocities along the center axis for water atomized by: (a) $\mathrm{N}_{2}$ at $100 \mathrm{psi}(0.68 \mathrm{MPa})$; (b) Ar at 100 psi. diameters for both flows were quite similar. It is possible that the primary particles formed during the disintegration of the melt column were even larger in diameter. This is suggested by the fact that the PDA technique cannot accurately measure drop sizes upstream a $50 \mathrm{~mm}$ distance from the tip of the melt tube, as Figure 7(a) indicates. Break up of the water particles was complete within $150 \mathrm{~mm}$ downstream of the point of initial atomization, resulting in a spray that consisted of particles 100 $\mu \mathrm{m}$ in diameter. In the case of Argon, completion of break up as a slight change in the $\mathrm{D}_{32}$ slope could be distinguished at approximately $200 \mathrm{~mm}$ below the die. The overall reduction in diameters for the Nitrogen flow was $80 \%$ while in the case of Argon it was $65 \%$. These figures, however, are by no means indicative of the atomization efficiency of the configuration, since they only serve as a comparison between the fragments of primary and secondary break up. In general, the velocity followed the inverse trend of the particle size, i.e. in the early atomization stages fragments decreased in size whilst gaining in velocity. After completion of the break up

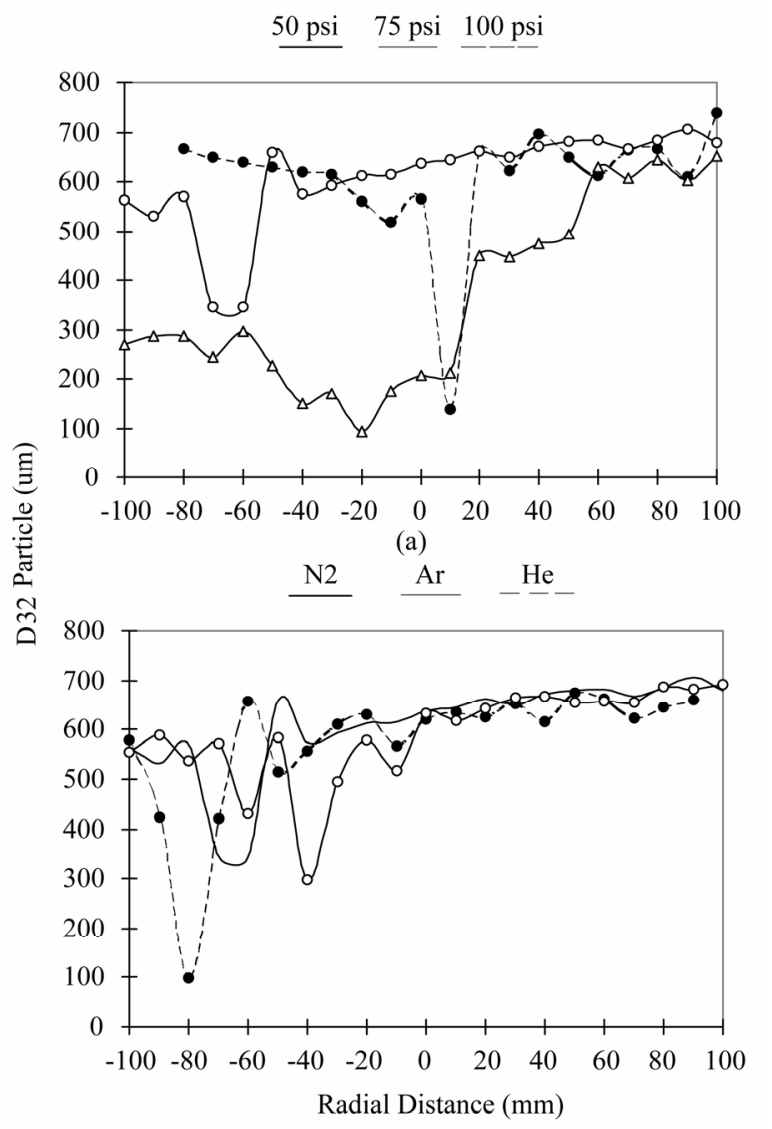

(b)

Figure 8. (a) Effect of the injection pressure of Ar on the radial variation of the $D_{32}$ size; (b) Effect of type of atomizing gas on the radial variation of the $D_{32}$ size. 
Table 1. Particle size, velocity and volume flux for water atomized at $50 \mathrm{psi}$ (0.34 MPa).

\begin{tabular}{|c|c|c|c|c|c|c|c|c|c|}
\hline & \multicolumn{3}{|c|}{ Nitrogen } & \multicolumn{3}{|c|}{ Argon } & \multicolumn{3}{|c|}{ Helium } \\
\hline $\begin{array}{c}\text { Radial } \\
\text { distance }(\mathrm{mm})\end{array}$ & $\begin{array}{l}\text { Velocity } \\
(\mathrm{m} / \mathrm{s})\end{array}$ & $\mathrm{D}_{32}(\mu \mathrm{m})$ & $\begin{array}{c}\text { Flux } \\
\left(\mathrm{cm}^{3} / \mathrm{s} * \mathrm{~cm}^{2}\right)\end{array}$ & $\begin{array}{l}\text { Velocity } \\
(\mathrm{m} / \mathrm{s})\end{array}$ & $\mathrm{D}_{32}(\mu \mathrm{m})$ & $\begin{array}{c}\text { Flux } \\
\left(\mathrm{cm}^{3} / \mathrm{s} * \mathrm{~cm}^{2}\right)\end{array}$ & $\begin{array}{l}\text { Velocity } \\
(\mathrm{m} / \mathrm{s})\end{array}$ & $\mathrm{D}_{32}(\mu \mathrm{m})$ & $\begin{array}{c}\text { Flux } \\
\left(\mathrm{cm}^{3} / \mathrm{s} * \mathrm{~cm}^{2}\right)\end{array}$ \\
\hline-100 & 4.609 & 554.2 & 7.482 & 0.397 & 564.2 & -1.143 & 3.053 & 579.1 & 5.395 \\
\hline-90 & 3.016 & 588.7 & 8.886 & 12.829 & 531.6 & 0.667 & 9.223 & 422.7 & 2.493 \\
\hline-70 & 7.707 & 571.8 & 18.563 & 7.228 & 345.1 & 0.652 & 12.563 & 421.4 & 4.59 \\
\hline-60 & 8.308 & 431.3 & 0.737 & 5.949 & 345.7 & 0.374 & 11.297 & 656.1 & 6.518 \\
\hline-50 & 15.363 & 583 & 20.503 & 13.164 & 660.3 & 27.612 & 18.361 & 514.7 & 4.274 \\
\hline-40 & 19.927 & 298.2 & 2.406 & 18.035 & 574.4 & 15.101 & 13.978 & 555.9 & -18.754 \\
\hline-20 & 18.286 & 578.5 & 12.516 & 19.739 & 612.1 & 13.564 & 18.464 & 630.5 & -15.865 \\
\hline-10 & 17.651 & 515.8 & 24.898 & 17.177 & 614.4 & 20.185 & 19.923 & 565.4 & 35.828 \\
\hline 0 & 16.736 & 632 & 104.02 & 18.058 & 637.8 & 29.867 & 18.153 & 621.4 & 75.328 \\
\hline 10 & 13.271 & 618.3 & 89.053 & 13.686 & 645 & 33.475 & 14.746 & 634.5 & 105.015 \\
\hline 20 & 11.494 & 642.1 & 117.685 & 11.1 & 661.5 & 65.545 & 12.318 & 625.9 & 76.575 \\
\hline 30 & 6.869 & 664.8 & 198.979 & 6.956 & 649.3 & 57.443 & 9.341 & 652.5 & 89.29 \\
\hline 40 & 5.738 & 667.2 & 276.583 & 5.942 & 672.8 & 63.682 & 6.804 & 615.3 & 58.847 \\
\hline 50 & 4.178 & 655.2 & 208.98 & 5.247 & 680.6 & 67.619 & 4.884 & 675.5 & 104.651 \\
\hline 80 & 3.078 & 687.4 & 113.705 & 3.501 & 684 & 42.072 & 2.585 & 646 & 18.388 \\
\hline 90 & 3.919 & 681.3 & 59.745 & 2.598 & 705.8 & 75.618 & 1.739 & 658.6 & 13.604 \\
\hline 100 & 3.163 & 692.6 & 46.703 & 3.953 & 678.5 & 15.569 & & & \\
\hline
\end{tabular}

process (e.g. $200 \mathrm{~mm}$ in the case of water/Nitrogen, see Figure $\mathbf{7 ( a )}$ the velocities remained constant within a limited distance and started decaying from that point downstream. Numerical data underlying to Figure 7 are presented in, Table 2.

The effect of the atomizing pressure on the particle size distribution inside the flow, in the case of Argon, is shown in Figure 8(a). $D_{32}$ decreased in all regions of the spray with increasing injection pressure of the gas phase. The primary fragments (in the centre of the spray) were not substantially affected by the change in injection pressure, while the fragments on the flow edge decreased in size. At $50 \mathrm{psi}(0.34 \mathrm{MPa})$ the majority of the spray, lying in the outer 160 of the spray cone, was made up by particles in the region of $650 \mu \mathrm{m}$. The inner region of the cone, within an angle of 4o from the centre axis, contained particles approximately $50 \%$ smaller compared to the rest of the spray. At 75 psi $(0.52 \mathrm{MPa})$ there was a wide variety of sizes along the radial direction, ranging from primary fragments in the centre of the flow, to the finer by $80 \%$ particles on the spray edge, the latter being finer than the ones at the same point produced at a pressure of $50 \mathrm{psi}(0.34 \mathrm{MPa})$. At an injection pressure of 100 psi $(0.69 \mathrm{MPa})$ the diameter of the larger particles in the centre of the flow was reduced while the size of the finest particles was not affected. The mean particle size and the distribution of diameters in the spray were greatly dependent on the type of the atomizing gas. A comparison of the diameters produced by Nitrogen, Argon and Helium, is shown in Figure 8(b), where the injection pressure of the gas was $50 \mathrm{psi}(0.34 \mathrm{MPa})$. All types of gases produced similar primary fragments that covered most of the spray area. Nitrogen and Argon produced the largest particles whilst Helium yielded 25\% finer particles along 
Table 2. Particle size and velocity for water atomized at $\mathbf{1 0 0}$ psi (0.68 MPa).

\begin{tabular}{|c|c|c|c|c|}
\hline & \multicolumn{2}{|c|}{ Nitrogen } & \multicolumn{2}{|c|}{ Argon } \\
\hline $\begin{array}{c}\text { Downstream } \\
\text { Distance }(\mathrm{mm})\end{array}$ & $\mathrm{D}_{32}(\mu \mathrm{m})$ & $\begin{array}{c}\text { Velocity } \\
(\mathrm{m} / \mathrm{s})\end{array}$ & $\mathrm{D}_{32}(\mu \mathrm{m})$ & $\begin{array}{c}\text { Velocity } \\
(\mathrm{m} / \mathrm{s})\end{array}$ \\
\hline 0 & & & & \\
\hline 10 & & & & \\
\hline 20 & & & 593.588 & 28.697 \\
\hline 30 & & & 604.923 & 30.053 \\
\hline 40 & & & 621.754 & 27.211 \\
\hline 50 & & & 632.666 & 27.093 \\
\hline 60 & 544.833 & 21.675 & 526.565 & 23.551 \\
\hline 70 & 531.433 & 18.286 & 486.413 & 25.384 \\
\hline 80 & 373.715 & 26.177 & 468.743 & 25.546 \\
\hline 90 & 436.078 & 25.095 & 575.132 & 27.055 \\
\hline 100 & 313.379 & 26.176 & 596.728 & 26.912 \\
\hline 110 & 223.32 & 25.545 & 561.224 & 29.751 \\
\hline 120 & 213.557 & 29.024 & 501.027 & 29.857 \\
\hline 130 & 248.314 & 29.399 & 455.383 & 30.491 \\
\hline 140 & 208.515 & 29.026 & 450.582 & 29.678 \\
\hline 150 & 117.699 & 29.411 & 472.545 & 30.128 \\
\hline 160 & 108.976 & 29.299 & 429.566 & 28.851 \\
\hline 170 & 140.312 & 29.563 & 398.381 & 30.137 \\
\hline 180 & 193.437 & 29.922 & 319.572 & 28.601 \\
\hline & & & 374.255 & 27.774 \\
\hline 210 & 95.953 & 29.158 & 361.140 & 28.376 \\
\hline 220 & 120.225 & 28.747 & 285.585 & 27.313 \\
\hline 230 & 128.376 & 29.242 & 256.276 & 29.007 \\
\hline 240 & 107.711 & 29.749 & 263.700 & 27.991 \\
\hline 250 & 104.118 & 27.507 & 261.941 & 27.704 \\
\hline 260 & 113.444 & 29.225 & 322.845 & 27.855 \\
\hline 270 & 97.457 & 28.187 & 253.981 & 28.875 \\
\hline 280 & 84.317 & 29.467 & 200.456 & 27.089 \\
\hline 290 & 96.488 & 29.468 & 207.036 & 28.986 \\
\hline 300 & 119.16 & 28.846 & 234.194 & 27.088 \\
\hline 310 & 96.471 & 29.329 & 262.674 & 26.515 \\
\hline 320 & 79.099 & 27.939 & 221.533 & 25.216 \\
\hline 330 & 94.125 & 26.964 & 241.347 & 26.66 \\
\hline 340 & 89.702 & 25.862 & 252.457 & 25.087 \\
\hline 350 & 89.6 & 28.215 & 253.982 & 26.716 \\
\hline 360 & 118.154 & 26.308 & 258.658 & 26.684 \\
\hline 370 & 116.628 & 25.67 & 273.361 & 24.693 \\
\hline 380 & 94.316 & 26.784 & 306.736 & 25.681 \\
\hline 390 & 85.658 & 26.584 & 224.107 & 24.143 \\
\hline 400 & 87.688 & 25.123 & & 22.105 \\
\hline
\end{tabular}

the central axis of the spray, compared to Nitrogen and Argon. Numerical data underlying to Figure 7 are presented in, Table 3.

The effect of the injection pressure on the distribution of particle velocities is shown in Figure 9(a), in the case of Argon. The mean components of the downstream velocities were normalized by the component measured on the theoretical centre axis of the spray for the flow generated by Argon at $100 \mathrm{psi}(0.69 \mathrm{MPa})$. The general trend suggests that the particle velocities increase with decreasing distance from the real axis of symmetry of the spray and with increasing atomization pressure. Every 50 psi $(0.34 \mathrm{MPa})$ increase in injection pressure seems to result in a $20 \%$ increase in the maximum velocity of the distribution. Figure 9(b) indicates that the type of atomizing gas does not affect the particle velocities substantially. Numerical data underlying to Figure $\mathbf{9}$ are presented in, Table 4.

\section{Conclusions}

High Speed Photography studies of the area of the spray

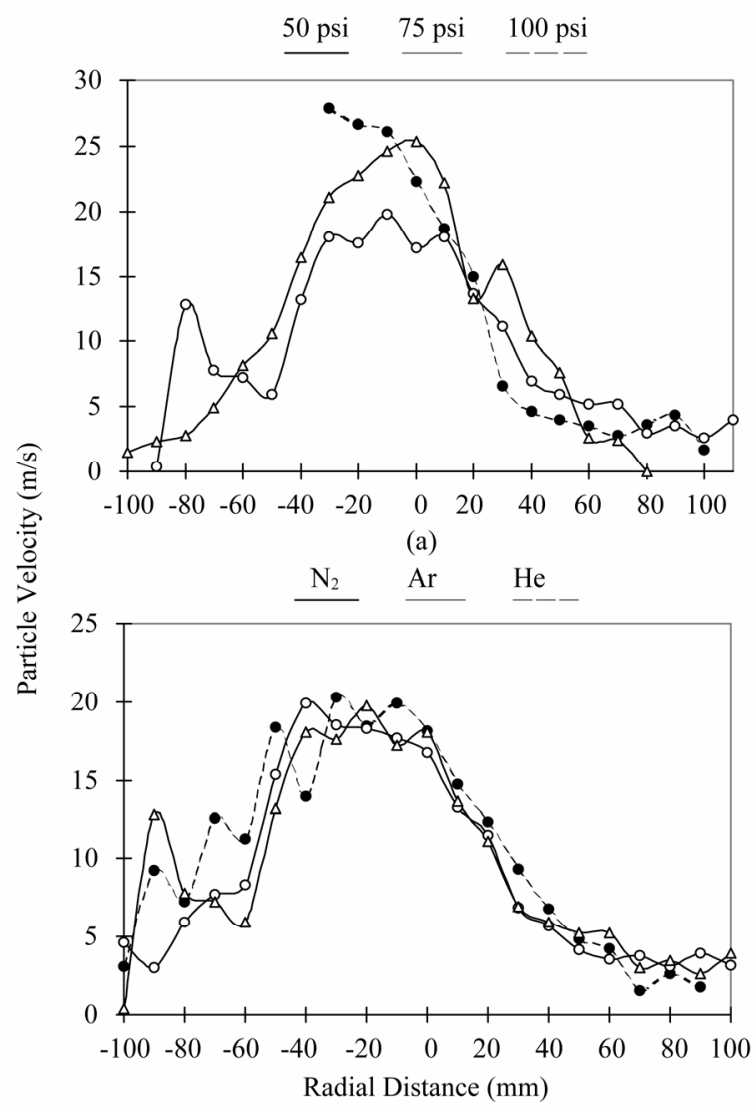

(b)

Figure 9. (a) Effect of the injection pressure of Ar on the radial variation of particle velocity; (b) Effect of type of atomizing gas on the radial variation of particle velocity. 
Table 3. Effect of injection pressure and type of atomizing gas on particle size.

\begin{tabular}{|c|c|c|c|c|c|c|}
\hline \multirow[b]{2}{*}{ Radial Distance (mm) } & \multicolumn{3}{|c|}{ Nitrogen } & \multicolumn{3}{|c|}{$50 \mathrm{psi}$} \\
\hline & $50 \mathrm{psi}$ & 75 psi & $100 \mathrm{psi}$ & Nitrogen & Argon & Helium \\
\hline-100 & 0.397 & 1.461 & & 4.609 & 0.397 & 3.053 \\
\hline-90 & 12.829 & 2.352 & & 3.016 & 12.829 & 9.223 \\
\hline-80 & 7.782 & 2.794 & & 5.946 & 7.782 & 7.276 \\
\hline-70 & 7.228 & 4.936 & & 7.707 & 7.228 & 12.563 \\
\hline-60 & 5.949 & 8.193 & & 8.308 & 5.949 & 11.297 \\
\hline-50 & 13.164 & 10.629 & & 15.363 & 13.164 & 18.361 \\
\hline-40 & 18.035 & 16.441 & & 19.927 & 18.035 & 13.978 \\
\hline-30 & 17.596 & 21.057 & 27.859 & 18.534 & 17.596 & 20.3 \\
\hline-20 & 19.739 & 22.776 & 26.7 & 18.286 & 19.739 & 18.464 \\
\hline-10 & 17.177 & 24.612 & 26.136 & 17.651 & 17.177 & 19.923 \\
\hline 0 & 18.058 & 25.4 & 22.268 & 16.736 & 18.058 & 18.153 \\
\hline 10 & 13.686 & 22.165 & 18.669 & 13.271 & 13.686 & 14.746 \\
\hline 20 & 11.1 & 13.243 & 14.916 & 11.494 & 11.1 & 12.318 \\
\hline 30 & 6.956 & 15.894 & 6.606 & 6.869 & 6.956 & 9.341 \\
\hline 40 & 5.942 & 10.366 & 4.659 & 5.738 & 5.942 & 6.804 \\
\hline 50 & 5.247 & 7.57 & 4 & 4.178 & 5.247 & 4.884 \\
\hline 60 & 5.219 & 2.637 & 3.542 & 3.561 & 5.219 & 4.212 \\
\hline 70 & 2.999 & 2.413 & 2.749 & 3.766 & 2.999 & 1.541 \\
\hline 80 & 3.501 & 0.042 & 3.597 & 3.078 & 3.501 & 2.585 \\
\hline 90 & 2.598 & & 4.372 & 3.919 & 2.598 & 1.739 \\
\hline 100 & 3.953 & & 1.666 & 3.163 & 3.953 & \\
\hline
\end{tabular}

close to the tip of the melt delivery tube on a close-coupled atomizer for a water-gas spray, indicated that at sufficiently high melt exit velocities and at relatively low atomization gas pressures the water column was deformed by sinusoidal antisymmetric oscillations. Symmetric oscillations that were superimposed on the antisymmetric mode had amplitudes about an order of magnitude smaller than those of the antisymmetric type. No crest, formed on the surface of the water column during the process of primary break up, was observed to reach an amplitude greater than roughly half the diameter of the water column. An increase of the diameter of the water column seemed to cause a reduction in the wavelengths disturbing its surface and the subsequent breakdown of the column. The use of Helium as the atomizing medium was found to cause the disintegration of the water column further upstream compared to Nitrogen. In addition, what looked like an unbroken core of water covered by dense spray, initiating from the tip of the melt delivery tube, was always shorter for the Helium than for the Nitrogen atomization runs. The diameter of the convergence region was found to be equal to $3 \mathrm{~mm}$ and was not affected by the gas injection pressure or the melt flow rate.

PDA measurements of the particle size and velocity in the water/gas jet indicated that the particle size decreases with increasing distance from the centre axis. Measurements of drop sizes along the centre axis of the flow indicated that break up was complete at a downstream distance of 150 to $200 \mathrm{~mm}$ from the die. Helium produced the finest particles and the highest particle velocity compared to Nitrogen and Argon. The radial distribution of particle size was sensitive to changes in the injection pressure of the gas but was not affected by the type of gas. As a general rule the velocities of the particles in the flow were not sensitive to the gas pressure or the nature 
Table 4. Effect of injection pressure and type of atomizing gas on particle velocity.

\begin{tabular}{|c|c|c|c|c|c|c|}
\hline \multirow[b]{2}{*}{ Radial Distance (mm) } & \multicolumn{3}{|c|}{ Nitrogen } & \multicolumn{3}{|c|}{$50 \mathrm{psi}$} \\
\hline & $50 \mathrm{psi}$ & $75 \mathrm{psi}$ & $100 \mathrm{psi}$ & Nitrogen & Argon & Helium \\
\hline-100 & 564.164 & 269.102 & & 554.217 & 564.164 & 579.054 \\
\hline-90 & 531.587 & 286.673 & & 588.707 & 531.587 & 422.689 \\
\hline-80 & 569.249 & 285.843 & 666.897 & 537.049 & 569.249 & 98.789 \\
\hline-70 & 345.137 & 245.258 & 650 & 571.783 & 345.137 & 421.375 \\
\hline-60 & 345.739 & 295.274 & 640 & 431.27 & 345.739 & 656.091 \\
\hline-50 & 660.251 & 226.992 & 630 & 582.973 & 660.251 & 514.699 \\
\hline-40 & 574.352 & 151.418 & 620 & 298.166 & 574.352 & 555.862 \\
\hline-30 & 592.781 & 170.734 & 614.405 & 493.848 & 592.781 & 611.016 \\
\hline-20 & 612.055 & 93.579 & 560 & 578.485 & 612.055 & 630.541 \\
\hline-10 & 614.374 & 174.542 & 517.619 & 515.82 & 614.374 & 565.442 \\
\hline 0 & 637.826 & 208.524 & 566.447 & 631,966 & 637.826 & 621.402 \\
\hline 10 & 645.004 & 211.822 & 138.862 & 618.253 & 645.004 & 634.517 \\
\hline 20 & 661.508 & 450.575 & 660.894 & 642.143 & 661.508 & 625.893 \\
\hline 30 & 649.298 & 445.947 & 623.267 & 664.796 & 649.298 & 652.534 \\
\hline 40 & 672.778 & 472.901 & 697.247 & 667.218 & 672.778 & 615.272 \\
\hline 50 & 680.584 & 493.555 & 650 & 655.248 & 680.584 & 675.549 \\
\hline 60 & 682.835 & 630.771 & 612.531 & 656.987 & 682.835 & 662.894 \\
\hline 70 & 666.44 & 606.578 & 664.22 & 655.005 & 666.44 & 623.471 \\
\hline 80 & 684.008 & 645.132 & 665.866 & 687.355 & 684.008 & 646.001 \\
\hline 90 & 705.803 & 602.265 & 611.01 & 681.273 & 705.803 & 658.556 \\
\hline 100 & 678.458 & 652.001 & 737.323 & 692.584 & 678.458 & \\
\hline
\end{tabular}

of the gas phase.

\section{REFERENCES}

[1] C. Dumouchel, J. Cousin and K. Triballier, "Experimental Analysis of Liquid-Gas Interface at Low Weber Number: Interface Length and Fractal Dimension," Experiments in Fluids, Vol. 39, No. 4, 2005, pp. 651-666. doi:10.1007/s00348-005-1005-5

[2] L. Fei, S. Xu and S. Huang, "Relaxation and Breakup of a Cylindrical Liquid Column," Science in China Series E: Technological Sciences, Vol. 51, No. 2, 2008, pp. 145-152. doi:10.1007/s11431-008-0018-8

[3] J. Shinjo and A. Umemura, "Simulation of Liquid Jet Primary Breakup: Dynamics of Ligament and Droplet Formation," International Journal of Multiphase Flow, Vol. 36, No. 7, 2010, pp. 513-532. doi:10.1016/j.ijmultiphaseflow.2010.03.008

[4] C. L. Ng, R. Sankarakrishnana and K. A. Sallam, "Bag
Breakup of Nonturbulent Liquid Jets in Crossflow," International Journal of Multiphase Flow, Vol. 34, No. 3, 2008, pp. 241-259.

[5] D. R. Guildenbecher, C. López-Rivera and P. E. Sojka, "Secondary Atomization," Experiments in Fluids, Vol. 46, No. 3, 2009, pp. 371-402. doi:10.1007/s00348-008-0593-2

[6] M. Arai, M. Shimizu and H. Hiroyasu, "Break-up Length and Spray Formation Mechanism of a High Speed Liquid Jet," Proceedings of the International Conference of Liquid Atomization and Spray Systems (ICLASS-88), London, 1988, pp. 177-184.

[7] H. Hiroyasu, M. Shimizu and M. Arai, "The Breakup of a High Speed Jet in a High Pressure Gaseous Atmosphere," Proceedings of the International Conference of Liquid Atomization and Spray Systems (ICLASS-82), Madison, 1982, pp. 69-74.

[8] R. Ingebo, "Experimental and Theoretical Effects of Nitrogen Gas Flow Rate on Liquid-Jet Atomization," Jour- 
nal of Propulsion and Power, Vol. 4, No. 5, 1988, pp. 406-411.

doi: $10.2514 / 3.23081$

[9] M. Kim and H. Jones, "Effect of Process Variables in Gas-Jet Atomization and Production of Multilayer Deposits," Proceedings of the Fourth International Conference on Rapidly Quenched Metals, Sendai, 1981, pp. 85-88.

[10] B. Pai and B. Nijaguna, "The Charecterization of Sprays," International Conference on Liquid Atomization and Spray Systems, Madison, 1982, pp. 29-35.

[11] R. Reitz, "Modeling Atomization Processes in High-Pressure Vaporizing Sprays," Atomization and Spray Technology, Vol. 3, No. 4, 1987, pp. 309-337.

[12] J. See and G. Johnston, "Interactions between Nitrogen Jets and Liquid Lead and Tin Streams," Powder Technology, Vol. 21, No. 1, 1978, pp. 119-133. doi:10.1016/0032-5910(78)80115-6

[13] A. Ünal, "Effect of Processing Variables on Particle Size in Gas Atomization of Rapidly Solidified Aluminium Powders," Materials Science and Technology, Vol. 3, 1987, pp. 1029-1039.

[14] S. Zanelli, "Behaviour of a Liquid Jet near the Nozzle," International Conference on Liquid Atomization and Spray Systems, 1988, pp. 1-14.

[15] C. Dumouchel, "On the Experimental Investigation on Primary Atomization of Liquid Streams," Experiments in Fluids, Vol. 45, No. 3, 2008, pp. 371-422. doi:10.1007/s00348-008-0526-0

[16] B. Vukasinovic, M. K. Smith, and A. Glezer, "Mechanisms of Free-Surface Breakup in Vibration-Induced Liquid Atomization," Physics of Fluids, Vol. 19, No. 1, 2007, pp. 012104-012104-15. doi:10.1063/1.2434799

[17] G. Gordon, "Mechanism and Speed of Breakup of Drops," Journal of Applied Physics, Vol. 30, No. 11, 1959, pp. 1759-1761. doi:10.1063/1.1735050

[18] F. Haas, "Stability of Droplets Suddenly Exposed to a High Velocity Gas Stream," AIChE Journal, Vol. 10, No. 6, 1964, pp. 920-924. doi:10.1002/aic.690100627

[19] J. Hinze, "Fundamentals of the Hydrodynamic Mechanism of Splitting in Dispersion Processes," AIChE Journal, Vol. 1, No. 3, 1955, pp. 289-295.

doi:10.1002/aic.690010303
[20] S. Mehrota, "Mathematical Modeling of Gas Atomization Process for Metal Powder Production," Powder Metallurgy International, Vol. 13, No. 2, 1998, pp. 80-84.

[21] M. Gorokhovski and M. Herrmann, "Modeling Primary Atomization," Annual Review of Fluid Mechanics, Vol. 40, No. 1, 2008, pp. 343-366. doi:10.1146/annurev.fluid.40.111406.102200

[22] H. P. Trinh, C. P. Chen and M. S. Balasubramanyam, "Numerical Simulation of Liquid Jet Atomization Including Turbulence Effects," Journal of Engineering for Gas Turbines and Power, Vol. 129, No. 4, 2007, pp. 920-928.

[23] J. Ishimoto, K. Ohira, K. Okabayashi and K. Chitose, "Integrated Numerical Prediction of Atomization Process of Liquid Hydrogen Jet," Cryogenics, Vol. 48, No. 5-6, 2008, pp. 238-247. doi:10.1016/j.cryogenics.2008.03.006

[24] K. Pougatcha, M. Salcudeana, E. Chanb and B. Knapper, "A Two-Fluid Model of Gas-Assisted Atomization Including Flow through the Nozzle, Phase Inversion, and Spray Dispersion," International Journal of Multiphase Flow, Vol. 35, No. 7, 2009, pp. 661-675. doi:10.1016/j.ijmultiphaseflow.2009.03.001

[25] G. S. E. Antipas, "Modeling of the Break up Mechanism in Gas Atomization of Liquid Metals, Part I. The Surface Wave Formation Model," Computational Materials Science, Vol. 35, No. 4, 2006, pp. 416-422. doi:10.1016/j.commatsci.2005.03.009

[26] D. Bradley, "On the Atomization of Liquids by HighVelocity Gases," Journal of Physics D: Applied Physics, Vol. 6, No. 14, 1973, pp. 1724-1736. doi:10.1088/0022-3727/6/14/309

[27] N. Dombrowski and W. Johns, "The Aerodynamic Instability and Disintegration of Viscous Liquid Sheets," Chemical Engineering Science, Vol. 18, No. 3, 1963, pp. 203-214. doi:10.1016/0009-2509(63)85005-8

[28] G. S. E. Antipas, "Modeling of the Break up Mechanism in Gas Atomization of Liquid Metals, Part II. The Gas Flow Model," Computational Materials Science, Vol. 46, No. 4, 2009, pp. 955-959. doi:10.1016/j.commatsci.2009.04.046

[29] G. Antipas, C. Lekakou and P. Tsakiropoulos, "The Break up of Melt Streams by High Pressure Gases in Spray Forming," Proceedings of the Second International Conference on Spray Forming, Swansea, 1993, pp. 15-24. 